\title{
IMF and economic reform in developing countries
}

Abbott, Philip; Andersen, Thomas Barnebeck; Tarp, Finn

Published in:

Quarterly Review of Economics and Finance

DOI:

10.1016/j.qref.2009.10.005

Publication date:

2010

Document version

Publisher's PDF, also known as Version of record

Citation for published version (APA):

Abbott, P., Andersen, T. B., \& Tarp, F. (2010). IMF and economic reform in developing countries. Quarterly Review of Economics and Finance, 50(1), 17-26. https://doi.org/10.1016/j.qref.2009.10.005 

Not for reproduction, distribution or commercial use.

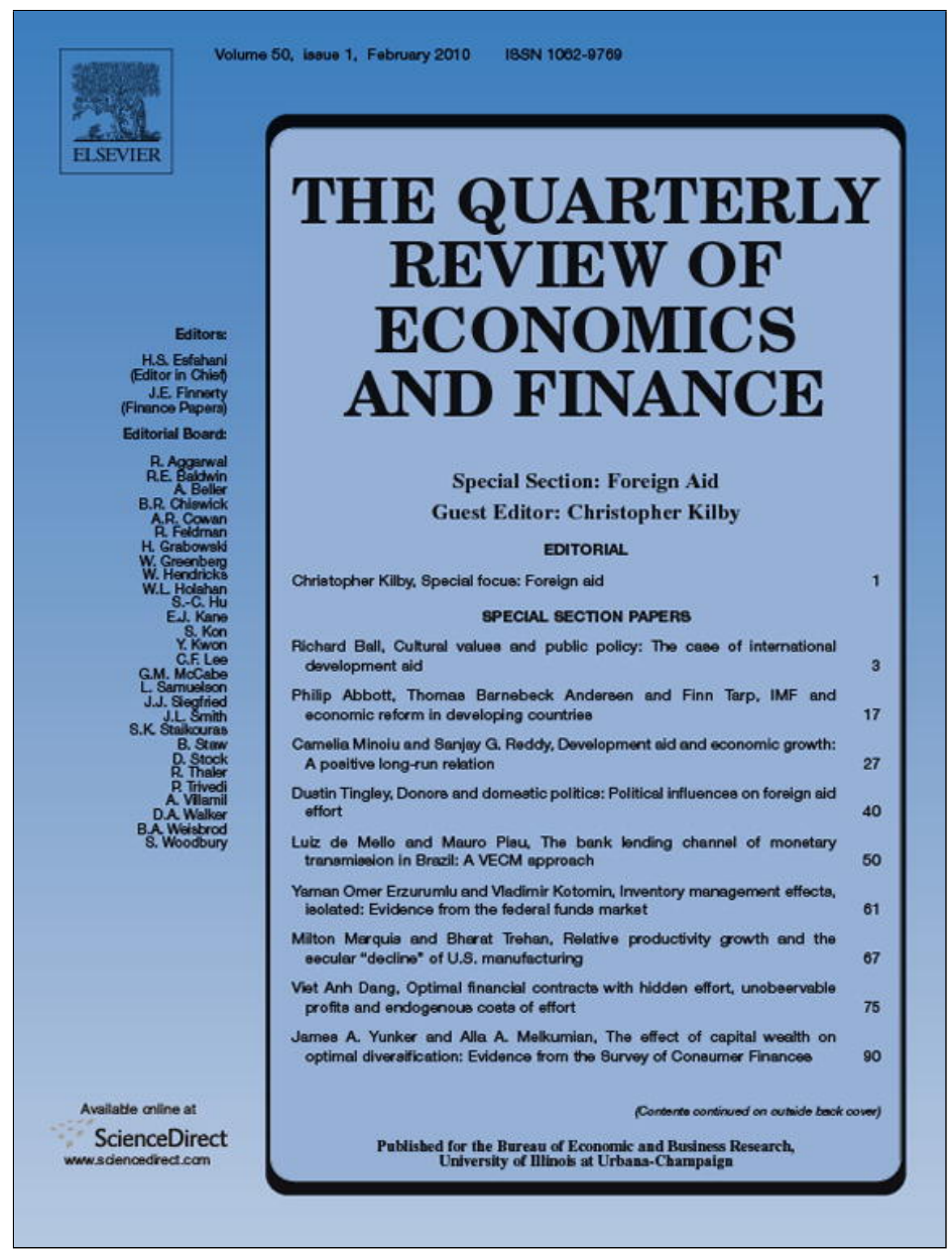

This article appeared in a journal published by Elsevier. The attached copy is furnished to the author for internal non-commercial research and education use, including for instruction at the authors institution and sharing with colleagues.

Other uses, including reproduction and distribution, or selling or licensing copies, or posting to personal, institutional or third party websites are prohibited.

In most cases authors are permitted to post their version of the article (e.g. in Word or Tex form) to their personal website or institutional repository. Authors requiring further information regarding Elsevier's archiving and manuscript policies are encouraged to visit:

http://www.elsevier.com/copyright 


\title{
IMF and economic reform in developing countries
}

\author{
Philip Abbott ${ }^{\mathrm{a}}$, Thomas Barnebeck Andersen ${ }^{\mathrm{b}, *}$, Finn Tarp ${ }^{\mathrm{b}, 1}$ \\ a Department of Agricultural Economics, Purdue University, Krannert Building, 403W State Street, West Lafayette, IN 47907-2056, USA \\ ${ }^{\mathrm{b}}$ Department of Economics, University of Copenhagen, Studiestræde 6, DK-1455 Copenhagen K, Denmark
}

\section{A R T I C L E I N F O}

\section{Article history:}

Available online 20 October 2009

\section{JEL classification:}

F3

F4

04

Keywords:

IMF programs

Structural conditionality

Economic growth

\begin{abstract}
A B S T R A C T
In this paper we assess the IMF approach to economic reform in developing countries. The impact of IMF program participation on economic growth has been evaluated empirically in a cross-country literature, with little evidence of IMF programs having been successful. This suggests that a fresh approach is in order. However, the cross-country approach is unlikely to provide a sound basis for drawing clear conclusions, so we review IMF programs from a different perspective, involving a broader literature on development strategy. In particular, it is widely accepted that a common characteristic of IMF programs is a high degree of policy rigidity. This is in contrast with studies which hold that unleashing an economy's growth potential hinges on a set of well-targeted policy interventions aimed at removing country-specific binding constraints. The process of locating constraints that bind involves growth diagnostics and policy trialing. This approach maintains that not all distortions are equally important and, by extension, not all policy reforms. From this point of view, IMF programs based on a list of standard conditionalities will not accomplish much. But policy trialing is more relevant to actors and entities with a broader, and more microeconomic, focus such as national policymakers and the World Bank. It is in choices among competing projects and programs that trial and error is most likely to be necessary. Nevertheless, reforms of the IMF such as the "streamlining initiative" should start from a good understanding of the reasons for adherence to policy orthodoxy. We discuss underlying institutional and organizational reasons for policy rigidity and consider some suggested reforms.
\end{abstract}

(c) 2009 The Board of Trustees of the University of Illinois. Published by Elsevier B.V. All rights reserved.

\section{Introduction}

The IMF is a lender of last resort to countries facing serious economic imbalances. Following the oil crises in the 1970s and the international debt crisis in the 1980s, the IMF focused its attention on devaluation and macroeconomic stability in order to restore external balances. The reform agenda embodied in policy conditionality soon expanded to address sectoral policies as well as institutional reforms. Policy conditionality in this way was broadened to encompass not only traditional balance of payments and monetary concerns but also development strategy and associated growth policies. The expansion in policy conditionality partly took place because, as was soon perceived, external balance and macroeconomic stability could not be achieved without changes in key sectoral policies.

The policy conditionality of the IMF quickly became the target of heavy criticism from both sides of the political spectrum (Bird

\footnotetext{
* Corresponding author.

E-mail addresses: abbottpc@purdue.edu (P. Abbott),

Thomas.Barnebeck.Andersen@econ.ku.dk (T.B.Andersen), Finn.Tarp@econ.ku.dk (F. Tarp).
}

\& Willett, 2004; IEO, 2007). ${ }^{1}$ On the left, IMF conditionality is typically viewed as harsh, intrusive, and ineffective; on the right, the habitual objection is that policy conditions are not enforced. Faced with these criticisms, the IMF has accepted that the proliferation of policy conditions went too far. Furthermore, the IMF has expressed a desire to re-focus attention to areas which are core competencies of the institution (IEO, 2007). In IMF lingo, conditionality must be streamlined. Yet the IMF continues to perceive conditionality as a useful instrument for encouraging economic reforms.

Over the years, the IMF has increasingly stressed that its policies should help lay the basis for promoting long-run economic growth (IEO, 2007; IMF, 2005). As such, devaluation, balance of payments equilibrium, and macroeconomic stability become intermediate targets that derive importance to the extent that they contribute to fostering economic growth. There is by now a wellestablished literature which evaluates the IMF against the goal of promoting long-run economic growth. While disagreement exists, the evidence is not entirely positive (Vreeland, 2006). However, the

\footnotetext{
${ }^{1}$ See Bird (2007) for a very comprehensive survey of the most recent research on
} the IMF. 
understanding of where the IMF seemingly went off target remains controversial.

Some claim that the IMF follows a one-size-fits-all approach. According to this view, the policy template used by the IMF is both unsound and overly rigid (Stiglitz, 2000, 2001, 2004; Vreeland, 2006). Others argue that incomplete compliance with conditionality is the main culprit. To the extent that program effectiveness requires adoption of the full gamut of IMF policy conditions, incomplete compliance will undermine the entire reform package (Krueger, 2004). Recent IMF thinking on conditionality is closer to this latter view (Rodrik, 2006). ${ }^{2}$ Unfortunately, it is very difficult to settle this debate using econometric evidence. Failure to demonstrate a positive effect from IMF program participation to economic growth does not allow us to discriminate in favor of either of these two views. Indeed, if we cannot fully account for the degree of compliance with conditionality (and this is very difficult), both views can with some right claim that no effect of reform initiatives is consistent with their diagnosis. What we can do, however, is to reason indirectly. The key observation is that compliance is only an issue to the extent that IMF conditionality offers the appropriate set of reforms (Goldstein, 2001).

This leads us to the emerging literature on growth diagnostics, which focuses on identifying and addressing key binding constraints to growth and policy trialing. Searching for appropriate economic policies and reforms that constitute a broad development strategy contains an element of trial and error (Easterly, 2008; Qian, 2003; Rodrik, 2005, 2006, 2008; World Bank, 2005). It involves taking risks, and it must build on local knowledge. Indeed, this literature suggests that flexibility and adaptability carry a high potential payoff. If the IMF is entrenched in orthodoxy, which we will argue is the case, one should not expect too much "growth bang from the IMF reform buck."

Policy trialing and adaptability to local circumstances are especially relevant to microeconomic decisions on projects and programs, where greater local variability and uncertainty on outcomes exists, and require a broad perspective on development strategy. To the extent that IMF reforms are streamlining conditionality to focus on core competencies, it will need to fit into a broader development strategy set in collaboration with other entities. Hence, we believe that the policy trialing and binding constraint diagnostic approaches are more relevant to national governments as they set priorities and interact with bilateral donors and the World Bank, and not just the IMF. Moreover, less policy rigidity by the IMF requires that it questions its underlying macroeconomic framework, a difficult task at the individual level.

Any reform of the IMF should start from understanding the underlying institutional and organizational reasons for IMF policy rigidity. Some explain policy rigidity by the fact that staff members face an incentive structure which discourages policy trialing and risk taking at the country level (Woods, 2006). Others argue that IMF recruitment policies sustain an intellectual monoculture (Momani, 2005). This leads us to consider the issue of organizational reform.

The paper is structured as follows: Section 2 provides a brief discussion of IMF conditionality. Section 3 turns to the empirical evidence on conditionality's track record with respect to fostering economic growth. Sections 4 and 5 discuss recent thinking on reform and growth, while Section 6 turns to a discussion of the apparent lack of policy trialing in the design of IMF programs. We reflect on the organizational culture within the IMF and discuss some reforms. Section 7 concludes.

\footnotetext{
2 The IEO (2007) finds extensive non-compliance with IMF conditions.
}

\section{Conditionality}

Conditionality serves a number of purposes. Above all, the IMF needs a mechanism to help ensure that countries pursue policies that will enable them to achieve external balance and eventually repay borrowed funds (Bird \& Willett, 2004; IMF, 2005). Moreover, conditionality provides the borrowing country with valuable information by clarifying the terms on which the IMF will make financial resources available (IMF, 2005). Adoption of IMF-supported policies is also meant to lay the foundation for a sustainable economic growth path over the longer term (IMF, 2005).

In the mid-1980s, structural conditionality gained prominence. It was aimed both at strengthening the sustainability of macroeconomic adjustment and at fostering growth. In the 1990s, the emergence of new IMF lending facilities for low-income countries, including transition economies, coincided with a significant acceleration in the use of structural conditions in IMF programs (IEO, 2007). While standard conditionality relies on quantitative targets for macroeconomic variables, structural conditionality requires changes in policy processes, existing legislation, and administrative and economic institutions. ${ }^{3}$ Typical structural conditionalities have included price and trade liberalization, privatization of state marketing monopolies, institutional reform of banking and the financial sector, anti-corruption measures, and legal reforms. Such measures were thought to increase static and dynamic efficiency, and ultimately accelerate growth. In addition, institutional reforms, such as strengthening the independence of central banks and the regulatory framework of the financial sector, were aimed at reducing domestic and external financial vulnerabilities.

The proliferation of structural conditions in the 1990s was met with increasing criticism outside the IMF. Many regarded them as intrusive and destructive for national ownership, undermining the very objectives of the programs the IMF was supporting. Many critics argued that the IMF was too mechanical and ideological in its use of structural conditions (IEO, 2007). The early 1990s saw a passionate debate on the relative merits of orthodox versus heterodox development theory and policy (e.g., Wade, 1990; World Bank, 1993). It has also been argued that IMF conditionality redistributes income away from the poor, and so has political consequences (Vreeland, 2003).

Partly as a response to these criticisms, the IMF issued a new set of Conditionality Guidelines in 2002, stressing the need for "parsimony" and a test of "criticality" for any variable selected for conditionality. These new guidelines also stress the need to seek country ownership. Program documents are to be prepared by the authorities in loan receiving countries (with the cooperation and assistance of IMF staff) and should reflect country level policy goals (IMF, 2005). ${ }^{4}$

The concept of national ownership is geared towards increasing compliance and is widely seen as a way to try to deal with the criticisms leveled at conditionality. If a country "owns" the policy changes, it can be assumed that it will try to implement them more readily; i.e., without IMF arm-twisting. This should also lead

\footnotetext{
3 The IEO (2007, p. 6) defines structural conditionality as "any program condition that is not a quantitative target related to financial programming [...]."

${ }^{4}$ The idea of country ownership is not new. Almost half a century ago, the IMF Managing Director, Per Jacobsen, pointed out that the IMF cannot just impose conditions and expect policy making to improve: "I must emphasize that such programs can only succeed if there is the will to succeed in the countries themselves. The IMF has always found people in these countries who know very well what needs to be done. The IMF does not impose conditions on countries; they themselves freely have come to the conclusion that the measures they arrange to take - even when they are sometimes harsh - are in the best interest of their own countries." (cited in Boughton, 2003, p. 5).
} 
to fewer and more focused structural conditions (IEO, 2007). The language of ownership includes a focus on broad participation of stakeholders within the country. Beyond ownership issues and parsimony in the application of program-related conditions, one finds calls to tailor programs better to country circumstances, to ensure effective coordination with other multilateral institutions, and to specify conditions clearly. In principle, ownership allows the IMF to respond to both the issue of a rigid policy template and the discussion of conditions being intrusive, at least ostensibly.

In practice, the streamlining initiative has not led to a reduction in the number of structural conditions (IEO, 2007). The average number per program/year has remained around 17 when comparing four-year windows before and after the start of the streamlining initiative in 2001. However, the initiative has significantly shifted the composition of structural conditions towards areas that (according to the IEO) are at the core of IMF competency. ${ }^{5}$ The IEO also asserts that compliance rates and program effectiveness are higher in these areas. However, program effectiveness relates to whether structural conditionality is "effective in bringing about follow-up structural reforms as well as whether reforms were sustained over time" (IEO, 2007, p. 16). This definition of program effectiveness is really only of second order. As argued by Goldstein (2001), even if countries consistently comply with the IMF structural conditions, this would only be desirable to the extent that such structural conditionality is effective in fostering economic growth. The first order definition of program effectiveness should be related to countries' economic development, captured by their rate of economic growth. According to this perspective, which presumes that growth rather than stabilization and external balance is paramount to IMF assistance, the critical question becomes: Does IMF structural conditionality add to countries' growth rates? One influential approach used to address this question is cross-country regressions. We turn to this literature in Section 3 before assessing in subsequent sections IMF conditionality in light of ongoing debates about what causes growth.

\section{Cross-country evidence}

This section provides a selective review of recent empirical literature on the IMF's track record in terms of fostering economic growth. While much of this literature has been surveyed elsewhere (e.g., Bird, 2007), our presentation contains some idiosyncrasies, and we attempt to provide a clear perspective on methodological pitfalls and identification assumptions. For purposes of readability, more technical discussions have been relegated to footnotes.

The key question this literature seeks to answer is: Do countries benefit from access to IMF loan programs or would they be better off without these programs? Two main problems make it difficult to answer this question satisfactorily. First, IMF loans are made in response to economic crisis. The set of program versus non-program countries differ because the former are in economic trouble while the latter might not be. Obviously, it would be unfair to blame the IMF for bad, pre-existing conditions, and there are no simple ways to establish the counterfactual needed for comparative purposes. ${ }^{6}$ Moreover, even assuming this selection issue

\footnotetext{
${ }^{5}$ Core IMF areas include taxation, public expenditure management, financial sector reform, trade issues, monetary policy, and exchange rate issues (IEO, 2007).

${ }^{6}$ Selection issues can be described in terms of an underlying counterfactual problem. That is, a given country has an outcome (GDP per capita growth rate, say) with treatment (under IMF program) and without treatment (not under IMF program). Because a country cannot at the same time both receive and not receive a treatment, the problem we face is one of missing data. Put differently, we don't know what the growth rate would have been for an IMF program country, had the country not been under the program. If we could assume that counterfactual growth rates in IMF
}

can be satisfactorily addressed, the economics profession is left with only an incomplete understanding of the complexities of the growth process. By implication, the growth regression is likely to be mis-specified. Nevertheless, the regression literature on the impact of IMF programs has directed almost all of its attention towards the selection problem. Some have relied on control function approaches (e.g., inverse Mills ratios) to construct selection corrections. Others have simply used IV methods with external instruments. In our view, the difficulties associated with a misspecified growth model are just as serious. ${ }^{7}$

Perhaps the most widely cited paper on the effects of IMF programs on economic growth is Przeworski and Vreeland (2000). They rely on a production-function approach in order to account for the sources of growth. To address the selection issue, Przeworski and Vreeland employ the somewhat complicated bivariate probit model with partial observability to construct selection corrections. $^{8}$ These corrections are then used as controls in their growth regression (alongside capital and labor) to calculate expected growth rates for each country during each year. These (hopefully) selection unbiased values are then averaged over all country-years for both country-years under and not under IMF programs. The difference is thus the net effect of IMF programs. ${ }^{9}$

Data span the 1970-2000 period and include for the most part some 79 developing countries. The measures included to represent IMF programs cover the four main types of IMF agreements: stand-by arrangement (SBA), the extended fund facility (EFF), the structural adjustment facility (SAF), and the enhanced structural adjustment facility (ESAF). ${ }^{10}$ The reason for including all programs is according to the authors that the fundamental objectives of these programs do not differ. ${ }^{11}$ Consequently, they only consider whether a country is under or not under a loan agreement without

programs countries are well approximated by developing countries not under IMF programs, the problem would (in principle) disappear. We would simply define the "average impact" of IMF programs as the difference between the average growth rate in the two groups of countries; i.e., program and non-program countries. However, since there is almost surely self-selection into treatment (i.e., countries that turn to the IMF are different from those that do not), this is not a valid strategy. We have to somehow account for this counterfactual problem in order to say something about whether countries benefit from access to IMF loan programs or not.

7 Numerous important methodological problems, which are often overlooked, plague this literature. First, papers relying on a production-function approach ignore the formal theory of aggregation, which shows that an aggregate production function only exists under some extremely unlikely assumptions (Fisher, 1969; Blackorby and Schworm, 1988; Felipe and Fisher, 2003; Temple, 2006). Indeed, regression specifications are likely to be ad hoc. Second, even sidestepping aggregation problems, the perpetual inventory method, which is used to construct a measure of aggregate capital, is beset by systematic measurement error (Pritchett, 2000). This makes causal inference fail. Moreover, even sidestepping the two aforementioned problems, Mankiw (1995) and Solow (2001) highlight that papers relying on Barro-type growth regressions suffer from a number of additional shortcomings, including simultaneity (left-hand side and right-hand side variables are jointly determined), multicollinearity (right-hand side variables are highly correlated), and a degrees of freedom problem (more variables affect growth than there are countries in the world).

8 They study participation in an IMF program as a joint decision by the country and the IMF.

9 This approach relies on very strong priors. Most importantly, it is assumed that unobserved factors, which influence the participation decision of the IMF and the country government, respectively, are independent. Vreeland (2003) discusses some of the difficulties of relaxing this assumption. To see what this assumption entails consider geostrategic importance, which arguably is unobserved. Pakistan, say, will benefit from its geostrategic importance in negotiating an IMF program, perhaps due to U.S. Treasury arm-twisting. At the same time, this may influence Pakistan's decision to approach the IMF. Yet such as scenario would violate the independence assumption.

10 In September 1999, the IMF terminated ESAF and replaced it with a new lending facility for low-income countries, the Poverty Reduction and Growth Facility (PRGF). 11 Conway (2006) raises the concern that papers stacking every IMF-supported program to get sufficient observations run the risk comparing apples and oranges. 
differentiation between different types of agreement. In the data sample, there are a total of 678 agreements, and out of these $88 \%$ are actually SBAs.

The average annual rate of growth of total income in the sample was 3.33\%. Countries participating in IMF programs grew at the rate of $2.04 \%$, while countries not under programs grew at $4.39 \%$. The difference amounts to minus 2.35 percentage points, and a key question is the extent to which this difference is due to respectively prior conditions or to IMF program participation. The conclusion of the Przeworski-Vreeland study is that IMF programs do "reduce growth while countries remain under and do not return benefits that would compensate the losses once they leave" (Przeworski \& Vreeland, 2000, p. 403). Put differently, countries not entering IMF programs grow faster than those entering, even when both groups face similar initial conditions. In fact, the authors find that of the negative growth differential, 1.53 percentage points is due to IMF programs (i.e., two-thirds).

Another influential paper on the effects of IMF programs on economic growth is Barro and Lee (2005). They employ a growth regression in which the right-hand side variables include different policy measures and analyze the growth effects of IMF programs for the period 1975-2000. Barro and Lee analyze SBA and EFF loans, but they report that all results hold when all IMF loan facilities are included in the measure of IMF presence. The point of departure is to view the IMF as a bureaucratic and political organization. In particular, Barro and Lee show that IMF loans are more likely to be approved and are likely to be larger when countries are more influential within the IMF. They gauge "country influence" by the size of the country quota at the IMF and by the number of the IMF professional staff originating from the country. In addition, they consider the political and economic connections of each country to the most influential members of the IMF; i.e., the United States and the major countries of Western Europe. To measure these connections, they employ voting patterns in the United Nations and the extent of bilateral trade linkages.

The empirical novelty is that they instrument IMF loan variables with predicted loan values based on IMF quotas and staff shares, fractions of UN votes along with the United States and the European countries, and the intensity of trade with the United States and the European countries. They employ these instruments in a growth regression and find that participation in IMF loan programs has a sizeable and significantly negative effect on economic growth. In sum, Barro and Lee corroborate the findings of Przeworski and Vreeland (2000). ${ }^{12}$

Dreher (2006) emphasizes that an important shortcoming of the above analyses is the failure to account for compliance with conditionality. The problem is that country economic performance will in all likelihood depend on program implementation. Conclusions based on analyses that fail to discriminate according to the degree of compliance among countries could well be biased. Dreher (2006) attempts to account for the degree of compliance in an evaluation of the effect of IMF programs on growth. He uses a dataset covering the period 1970-2000 with some 98 developing countries. He uses the same explanatory variables as Barro and Lee (2005) plus additional variables to account for compliance with conditionali-

\footnotetext{
12 The identification assumption in the Barro-Lee study is that the aforementioned political economy variables are exogenous with respect to economic outcome variables such as real per capita GDP growth. That is, factors which influence a country's growth trajectory should influence neither the number of residents seeking employment at the IMF nor their voting behavior in the United Nations. Put differently, the identification strategy asks us to believe that a high share of Argentineans employed by the IMF should not be a reflection of the fact that Argentina has experienced financial crises in the past, due to for instance an ingrained habit of populist economic policies.
}

ties. Dreher makes use of three different compliance measures: (i) a dummy variable for the suspension of an IMF program developed by Edwards (2001); (ii) the share of the agreed loan amount actually disbursed proposed by Killick (1995); and (iii) a dummy variable equal to one if at most $25 \%$ of the amount which would be available for a certain year under equal phasing remained undrawn and zero otherwise, a measure proposed by Dreher (2003). ${ }^{13}$

Dreher finds evidence that participation in IMF programs reduces economic growth, and this continues to be the case even after controlling for compliance with conditionality. Interestingly, compliance with conditionality does seem to somehow reduce the overall negative effect of IMF programs. Even so, Dreher concludes that the overall impact remains substantially negative after taking compliance into account. ${ }^{14}$

Easterly (2005a, 2005b) makes a departure from the IV/counterfactual-based studies, and provides an analysis of what he denotes as informative statistics. His fundamental insight is that adjustment loans are dependent events: there is information in the frequent repetition of loans to the same country. Easterly first notes that the probability of receiving an IMF or World Bank adjustment loan is not decreasing in the number of loans already received. If loans work according to intention (i.e., if they are effective), we should expect this conditional probability to be decreasing. Secondly, he shows that the macroeconomic experience of the top 20 recipients of IMF or World Bank adjustment loans over the $1980-1999$ period is, on average, no different from that of the average group of developing countries, and this latter group contains countries with extreme macroeconomic distortions. Moreover, the group of countries receiving adjustment loans had a very high variance of macroeconomic outcomes. This group includes countries with strong growth and no major macroeconomic imbalances such as Uganda and Pakistan, and it includes disasters such as Zambia and Cote d'Ivoire. According to Easterly, the disasters provide bounds on our intuition on counterfactual outcomes: it is necessary to believe that disaster cases such as Zambia would have done even worse without repeated adjustment lending. Obviously, selection bias can still be at work for countries receiving repeated loans, but this raises the important question as to why the IMF and the World Bank made new loans to countries that so obviously failed to deliver reform in response to old loans. Thirdly, Easterly considers the transition probability from IDA (International Development Association) status into HIPC (Heavily Indebted Poor Countries) debt relief, conditional on adjustment lending. IDA countries that received above-average adjustment lending were much more like to become HIPCs as compared to IDA countries receiving below-average adjustment lending. Easterly (2005, p. 20) concludes that "[t]he big stylized facts of adjustment lending suggest that structural adjustment did not succeed in adjusting macroeconomic policy and growth outcomes very much."

To be sure, there are also studies such as Dicks-Mireaux, Mecagni, and Schadler (2000) that find a positive impact of IMF programs on growth. ${ }^{15}$ Dicks-Mireaux et al. also subject their sta-

\footnotetext{
13 Vreeland (2006) contains a good discussion of how to measure compliance.

14 A problem with Dreher's approach is that each of the three measures used correspond with extreme non-compliance with structural conditionality. In our experience, it is often the case that countries continue to receive the full amount of agreed upon loans even when they are not in full compliance. An alternative interpretation of Dreher's results is simply that the countries which are the furthest from IMF conditions realize lower growth rates.

15 Conway (2006) summarizes research that finds a reduced growth rate in the initial program year but a higher growth rate in the second year. This suggests that measuring the effect over a longer period could lead to different conclusions. Moreover, Fischer (2005) even argues that the "consensus" view is that the growth
} 
tistical model to a battery of diagnostic tests, and this leads the authors to conclude: "Indeed, on the basis of this study, it cannot be ruled out that the inherent limitations of panel data covering countries facing highly diverse circumstances render it impossible to obtain reliable estimates of the independent effects of IMFsupported programs" (Dicks-Mireaux et al., 2000, p. 522).

The empirical evidence covered here is not favorable to the IMF. At the same time, we concur with Dicks-Mireaux et al. (2000) that the methodological complexities are probably too involved for the cross-country literature to be able to provide a sound basis for drawing unambiguous conclusions as to the impact of IMF structural conditionality. We therefore proceed in Sections 4 and 5 to review IMF programs from a different perspective, first assessing the IMF's changing theoretical paradigm and then considering a broader literature on growth determinants as it relates to IMF conditionality.

\section{Institutions fundamentalism}

Alongside the studies addressing the growth impact of IMF programs there is a literature that tries to understand the importance of macroeconomic policies for growth. Much of this literature attempts to make a distinction between policies and institutions (Easterly, 2005a, 2005b). Countries with poor macroeconomic policies, including high inflation, large budget deficits, and overvalued exchange rates, have definitely suffered more macroeconomic volatility and grown more slowly during the postwar period. However, countries with poor macroeconomic policy records also have weak institutions. Poor macroeconomic policies are not pursued because politicians believe that high inflation or an overvalued exchange rate foster economic growth. Instead, they reflect, according to Acemoglu, Johnson, and Robinson (2003), underlying institutional challenges. To illustrate, an overvalued exchange rate offers one avenue by which resources can be funneled away from the agricultural sector towards urban interests, a policy intended to keep incumbent governments in power in "institutionally weak" societies. According to this logic, poor macroeconomic policies are symptoms of weak institutions. Indeed, Acemoglu et al. (2003) show that once they control for the causal effect of institutions (or more accurately, the historically determined component of institutions) on volatility and economic performance, macroeconomic policies no longer play a direct role. ${ }^{16}$ This result is reinforced by what appears as a macroeconomic conundrum: Why has improved macroeconomic stability not led to the expected growth payoff? Over the 1990s, for instance, developing countries made real progress in terms of fiscal consolidation and inflation, an improvement that was also instrumental in bringing about a reduction in output volatility (Montiel \& Servén, 2006). Yet the growth dividend certainly fell far short of expectations (Easterly, 2001; Montiel \& Servén, 2006).

Montiel and Servén (2006) argue that insufficient institutional reform holds the key to this puzzle. With forward-looking private agents, decisions to invest are influenced by both current macroeconomic stability and the perceived likelihood of future macroeconomic stability. To significantly influence growth, cur-

\footnotetext{
rate is reduced initially, but that it revives as structural reforms take root.

16 Glaeser et al. (2004) present a conflicting view. They argue that the measures of institutions employed are flawed, and more appropriate measures are not significant determinants of growth. In addition, Albouy (2008) questions the construction of the historically determined component of institutions employed by Acemoglu et al. (2003) (i.e., the celebrated settler mortality instrument). Indeed, Albouy demonstrates that the "corrected" settler mortality instrument no longer spans exogenous variation in institutions. This renders the conclusions of Acemoglu et al. (2003) problematic.
}

rent macroeconomic stability must be seen by the private sector as credible and sustainable. That is, it must be indicative of a permanent shift in the macroeconomic policy regime. For this to happen, macroeconomic policy must be built on solid institutional foundations. More specifically, a temporary reduction in deficit monetization is not too difficult to achieve, but unless long-lasting increases in the primary surplus are somehow institutionalized, continuing pressures on the government budget will increase the likelihood of future monetization (Montiel \& Servén, 2006). This discourages private investment and thus economic growth.

This type of reasoning has led to a sort of "institutions fundamentalism" (Rodrik, 2006). While "getting prices right" was the message of the original Washington Consensus in the early 1980 s, "getting institutions right" has been in vogue over the past decade. It has become part of what Rodrik (2006) calls the augmented Washington Consensus. Specifically, Rodrik (2006, p. 978) defines the augmented Washington Consensus as the original Washington Consensus plus the following items: corporate governance, anti-corruption, flexible labor markets, WTO agreements, financial codes and standards, "prudent" capital-account opening, non-intermediate exchange rate regimes, independent central banks/inflation targeting, social safety nets, and targeted poverty reduction. Consequently, the policy template used by the IMF has undergone evolutionary change (i.e., from original to augmented Washington Consensus) as manifest by the IMF's increasing advocacy of institutional reforms.

Such evolutionary change has, by and large, been perceived as "sound economics" by the mainstream of the economics profession. Indeed, it is in full accord with the "institutions rule" literature (see Rodrik, Subramanian, \& Trebbi, 2004). Yet, as we will argue below, heterodox approaches to economic development have been seriously challenging this mainstream view. In fact, we believe that the heterodox stance is slowly becoming the new mainstream view (see World Bank, 2005). The unclear track record associated with structural conditionality in conjunction with the manifest use of heterodox policies in rapidly growing Asian economies (especially China) has greatly accelerated this process. In contrast, the IMF maintains that inadequate compliance and backsliding are at the core of the lack of success. Rodrik (2006, p. 977) summarizes the IMF position as "do more of the same, and do it well." This probably also explains why the IEO (2007) chose to define program efficiency in terms of being effective in bringing about follow-up structural reforms as well as whether reforms were sustained over time as opposed to fostering economic growth. ${ }^{17}$ By a revealed preference type argument, this suggests that the IEO deems that the current IMF policy template is appropriate.

\section{Binding constraints}

Critics hold that the type of institutional reforms pursued by the IMF is heavily tilted towards a best-practice model (Bromley \& Yao, 2006; Easterly, 2008; Evans, 2004; Rodrik, 2006, 2008). The best-practice model presumes that it is possible ex ante to settle on a unique set of appropriate institutional arrangements (best-practices), and that convergence towards these institutional arrangements is attractive. Paradoxically, the best-practice model does not fit well with the fact that many growth "miracles" are characterized by heterodox institutional arrangements (Rodrik, 2005). China and Vietnam, for instance, continue to retain many socialist characteristics. Some authors also emphasize the importance of building reforms on pre-existing institutions and making reforms

\footnotetext{
17 This touches upon our distinction in Section 2 between first order (growth) and second order (compliance) issues.
} 
incentive compatible (Qian, 2003; Rodrik, 2005). Rodrik (2005) asserts that the first order principles of reform should embody market-oriented incentives, macroeconomic stability, and outward orientation, but these "principles" can be implemented under a variety of institutional arrangements. He argues that this is indicative of huge "missing links" in our knowledge of what generates sustained economic growth.

Turning to more specific criticisms of the best-practice model, it can be highlighted that it ignores both the existence of binding constraints (and, by implications, a sense of reform priority) and second best issues. ${ }^{18}$ Rodrik (2007) provides a nice discussion of these two concepts against the backdrop of the Chinese agricultural reform. In 1978, a common suggestion was that agricultural sector distortion was the most important constraint holding back the Chinese economy. At the time, however, most economists would probably have opted for abolition of state controlled prices and the privatization of farmland. However, such policies would have been dangerous as has been amply demonstrated elsewhere. For instance, since the difference between purchase and sales prices of crops formed part of the tax base, bringing the state procurement system to an end would have diminished a significant source of government revenue. Such second best concerns must be factored in when designing reforms. The Chinese dual-track approach to agricultural market liberalization (i.e., freeing output prices at the margin while keeping the plan intact and maintaining distorted fertilizer prices) did just that (Qian, 2003; Rodrik, 2007). ${ }^{19}$

Collier (2007) provides an illustrative example of the "specificity" of binding constraints. Bangladesh and Chad both have endemic corruption. Yet despite being a very corrupt country, Bangladesh has experienced decent growth. Chad, on the other hand, has not done well. According to Collier, this is due to differences in opportunities. Bangladesh is a resource-scarce, coastal, low-income country. Its development path is clear: export laborintensive manufactures and services. This development strategy is not very demanding in terms of government. Not so for Chad, an oil-rich, aid-abundant, landlocked, low-income country. Chad is not well-located for exporting, and to make good use of aid and oil requires a reasonably good government. That is, Chad's government must do more than "do-no-harm", it must really do some good. Corruption is thus much more harmful for Chadians than for Bangladeshi. In fact, what Collier is saying is that corruption is a binding constraint in Chad, but not in Bangladesh.

The importance of binding constraints is backed by empirical results reported in Hausmann, Pritchett, and Rodrik (2005a). These authors have studied a set of growth accelerations (i.e., increases in growth of GDP per capita) that were sustained for at least eight years, that had a post-acceleration growth rate of at least $3.5 \%$ per year, and (to rule out cases of pure recovery) that had

\footnotetext{
18 The theorem of the second best states that removing an arbitrarily chosen distortion in an economy with multiple distortions may reduce welfare (Lipsey and Lancaster, 1956).

${ }^{19}$ As noted by a referee, second best issues also feature prominently in the literature on the optimal sequencing of reforms (see Edwards, 1989; Rybczynski, 1991). For instance, the conventional approach to stabilization under structural adjustment programs during the 1980s was based on a two-step approach. First, macroeconomic stabilization was seen as necessary in order to achieve equilibrium and for optimization of (static) welfare. Second, microeconomic reforms were deemed necessary in order to ensure the proper working of the price mechanism. Rybczynsk (1991) emphasizes that particularly the second step has weak theoretical foundations when viewed through the lens of the theorem of second best. In fact, all reforms have to be carried out simultaneously in order to increase welfare unambiguously, as any perturbation of the order of implementation may lead to a loss in welfare. Accordingly, the timing and interrelation of microeconomic (or structural) reforms in relation to macroeconomic stabilization remains without a firm
} theoretical foundation. post-acceleration output exceeding the pre-episode peak level of income. Using a large cross-country sample spanning the period since the 1950s, Hausmann et al. find 80 episodes of growth accelerations. Of these growth accelerations, only $14.5 \%$ are accompanied by standard macroeconomic reforms. That is, more than $85 \%$ of all growth accelerations are not associated with reforms. Hausmann et al. conclude that growth accelerations are mainly caused by idiosyncratic, and often small-scale, changes. This is consistent with the idea that a set of country-specific binding constraints may in fact be holding down the economy's growth rate.

Hausmann, Rodrik, and Velasco (2005) propose a theoretical framework for thinking about binding constraints to growth, which is rooted explicitly in a second best context. The governing idea is that a few focused policy interventions (i.e., removal of a small number of key binding constraints to growth) will have a larger impact on growth than the traditional approach based on implementing a fairly long list of reforms.

To focus their ideas, Hausmann et al. consider an economy where market imperfections and distortions are pervasive. From the formal theory of second best we know that removing an arbitrarily chosen distortion in an economy with multiple distortions may reduce welfare. The only way a reformer can be sure to increase welfare is by wholesale reform. This is obviously not operational since it requires complete knowledge of all distortions in the economy, including those that do not arise as a result of some government intervention. In an economy with multiple distortions, a marginal reduction in a single distortion leads to a direct effect on aggregate welfare by an amount given by the Lagrange multiplier associated with the constraint linked with this distortion. In other words, the multiplier is the marginal benefit in welfare units from slightly reducing the specific distortion, disregarding the effects on all other distorted activities. The more the distortion binds, the larger is the direct effect. There are also indirect effects from reducing the distortion on the targeted activity. There is an effect on the weighted sum of the wedges between social and private valuations on all other activities, where the weights are the own-multipliers of each distorted activity. If, on average, the effect is to reduce these wedges, ceteris paribus, the reduction in the targeted distortion gives rise to an additional welfare benefit. If, however, it tends to increase the wedges, the welfare gain is reduced or, if the indirect effect is sufficiently strong, turned into a welfare loss. This is the theory of second best in operation.

Hausmann, Rodrik, et al. (2005b, p. 5) maintain that the current thinking on policy reform forgets all about the theory of second best and simply goes for "whatever reforms seem to be feasible, practical, politically doable, or enforceable through conditionality. ${ }^{20}$ This is a "shotgun" approach to reform that implicitly relies on the notions that (i) any reform is good; (ii) the more areas reformed, the better; and (iii) the deeper the reform in any area, the better." In the presence of multiple economic distortions, we have no assurance that a given reform is welfare enhancing. Welfare need not be increasing in the number of reform areas, except (in theory) in the extreme case of wholesale reform.

According to Hausmann et al. reform priorities should be designed according to the magnitude of direct effects cognizant of second best interactions that could reverse positive welfare effects. Their (implicit) empirical assumption is that direct effects from eliminating the most binding constraints will dominate deleterious indirect effects. They attempt to make their approach operational by developing a "tree", close in spirit to the trouble-shooting

\footnotetext{
${ }^{20}$ While Hausmann, Pritchett, et al. (2005a) address policy reform and conditionally more generally, we read Rodrik (2006, p. 977) as directing this critique particularly at the IMF.
} 
sections of product manuals (Dixit, 2007). They suggest that policy practitioners should look not at specific distortions, but at proximate determinants of growth (saving, investment, education, productivity, infrastructure, etc.) in order to identify symptoms that may be associated with poor growth. ${ }^{21}$ Once it is known where to focus, reformers can look for associated economic distortions whose removal may be expected to produce the "biggest bang for the reform buck."

While the fundamental idea in growth diagnostics (i.e., that the removal of a set of key constraints will have a larger impact on growth than the traditional approach based on a longer list of reforms) has much intuitive appeal, the framework remains incomplete in a formal (mathematical) sense. Firstly, as noted by Rodriquez (2005), from the theory of non-linear programming we know that changing one policy at a time will generally be a very inefficient way of reaching an optimal outcome. Secondly, and most important, the robustness of the growth diagnostics approach vis-à-vis second best problems is actually unknown. ${ }^{22}$ We know from general equilibrium analysis that if a government for instance wants to select a public investment program based on generated income, selecting the one with the highest value added may not in general be optimal. Another investment, with lower value added, may have a higher production income multiplier (Raa, 2005). That is, we cannot in general say that looking for higher direct effects is the optimal path to follow. ${ }^{23}$

Consequently, the main attractiveness of the growth diagnostics framework lies not in its immediate practical applicability and/or formal elegance. Instead, it lies in its insistence that not all distortions are equally important. As such, growth diagnostics encourages us to set apart reforms that are essential for growth from those that are desirable (Leipziger \& Zagha, 2006). To the extent that the capacity for reform is limited in many developing countries, this is important.

In sum, while on a conceptual level the binding constraints approach is appealing, an application via growth diagnostics is limited by our imperfect knowledge of the impact of alternative development strategies and policies. This suggests that searching with experimentation and learning is required in order to achieve better reform outcomes. Recent literature has emphasized the role of policy experimentation in the process of reforming an economy (e.g., Heilmann, 2008). It must be stressed, however, that policy experimentation (or policy trialing) is not free-wheeling trial and error. It is an open-minded and purposeful activity rooted in economic theory and local knowledge. Policy trialing by IMF staff would surely imply that conditionality is allowed to diverge from the principles of the augmented Washington Consensus. Mission staff would, for example, be allowed to explore and put programs together without immediate devaluations. Looser monetary and fiscal policy in times of recession would also be considered,

\footnotetext{
${ }^{21}$ According to Dixit (2007), this approach is attractive. It looks at multiple dimensions of economic outcomes and it tries to narrow down causes from a set of multiple possibilities. However, the sequential mode of thinking based on a given tree structure is problematic as it does not take into account the probabilistic nature of the exercise. This shortcoming leads Dixit to propose a Bayesian approach to growth diagnostics, which allows reformers to explicitly make probabilistic statements about binding constraints. Carlin and Seabright (2007, p. 3) add that "we need to add an assessment of the feasibility and the costs of improving the relevant constraints." 22 Jones (2008), however, constructs a model in which linkages and complementarities can amplify the macroeconomic effects of small microeconomic distortions. He argues that in this model, the approach of Hausmann, Rodrik, et al. (2005b) would work well. This suggests that focusing on key binding constraints could be effective. Yet indirect effects can obviously not be ignored.

${ }^{23}$ Further complications include how to address uncertainty and whether the objective of policy makers should be to maximize expected value or ensure the
} best outcome under worst-case scenarios. and continuation of certain aspects of trade protection would not be automatically ruled out. A key role for government in areas normally targeted for privatization would also be feasible, and a considerable degree of restraint would be characteristic when deregulating the banking sector in order to reduce the risk of financial crisis.

\section{Towards policy trialing}

The policy trialing and binding constraints framework is best suited to assessing the critical elements of broad development strategy. Indeed, this framework emerged within a literature that is much broader than the IMF conditionality reform debate. Policy trialing is most relevant to project and program decisions, where country diversity and outcome uncertainty are greatest; and it is best implemented by entities that must take a broad perspective to development, which should be the focus of national governments. If the IMF streamlines its conditions so as to focus on core competencies, the IMF will be less involved in the broad range of development decisions than it has been in the past. The World Bank and bilateral donors, with their focus on microeconomic decisions, would be the entities most concerned with implementing these new approaches. The IMF would need to coordinate with the World Bank, and with bilateral donors, more so than it has in the past (Malan, 2007). To the extent that policy trialing is relevant to the IMF, it will be in macroeconomic policy.

Currently, however, the IMF is not well-suited to adopt macroeconomic policy trialing as an approach to reform. There are at least two reasons for this. Firstly, the IMF is plagued by a lack of intellectual diversity (so-called intellectual monocropping) and a policy template that is overly rigid (e.g., Evans and Finnemore, 2001; Stiglitz, 2004; Momani, 2005, 2007; Taylor, 1997). Secondly, IMF staff face an incentive structure that does not encourage risk taking (Woods, 2006). In what follows we elaborate on these assertions.

Prominent critics such as Stiglitz (2004) have argued that the IMF policy template is excessively neoclassical and based in large part on ideology. ${ }^{24}$ The IEO (2004, p. 17) evaluation of the Poverty Reduction Strategy observes that a major external criticism of the IMF is that "[a]lternative policy options - especially ones that deviate from the so-called 'Washington Consensus' - are rarely explored." Moreover, as an integral part of the millennium review of conditionality, the IMF held and participated in numerous seminars around the world. According to Boughton (2003), one of the

\footnotetext{
24 The IMF's adherence to orthodoxy has probably nowhere been as pronounced as in the case of capital-market liberalization. According to Stiglitz (2004), the IMF attempted to change its charter in September 1997 in order to force capital-market liberalization on reluctant developing countries, and they did so despite a lack of empirical evidence that capital-market liberalization would benefit developing countries. In fact, World Bank researchers, among others, had shown that such policies were systematically associated with increased instability (e.g., Demirgüz-Kunt and Detragiache, 1998). Even so, IMF's Managing Director kept calling for capitalmarket liberalization two years after the Asian crisis, an event that had clearly shown the risks associated with this policy. According to Stiglitz, the IMF insistence on capital-market liberalization was based neither on theory (when theory was invoked, it was the neoclassical model with no imperfections; not the asymmetric information model, which holds radically different implications) nor empirics. Rather, it was based in ideology. It is quite revealing to look at how the capitalmarket liberalization thesis has evolved in light of actual liberalization experience. The disastrous results of liberalizations in the 1970s and 1980s, particularly in the Southern Cone countries, induced a first round of revisions. It was argued that macroeconomic instability and inadequate bank supervision were the main culprits. Later, the optimal order of liberalization received substantial attention. Liberalization needed sequencing and reforms had to be managed carefully in order to become successful. In view of the Asian crisis, arguments addressing moral hazard problems in relation to deposit insurance were advanced. Yet, during all these rounds of post hoc revisions, the fundamental premise that capital market liberalization would benefit developing countries was never (openly) questioned.
} 
strongest and most consistent criticisms expressed at those seminars was that countries had too little flexibility in deciding how or when to implement reforms.

This does not mean that the IMF policy template has not evolved. As argued above, conditionality has broadened (i.e., moved from the original to the augmented Washington Consensus) but the original thinking remains entrenched. ${ }^{25}$ Easterly (2005b, p. 3) captures this well: "IMF and World Bank conditionality has evolved over time, but there is a common element of macro adjustment and getting prices right that has remained constant from the beginning."

Momani (2005) has conducted interviews with former IMF staff and executive directors, who do not find the IMF's economic paradigm wrong or misguided. Many recognize that the IMF has a homogenous and monolithic nature, but stress that no alternative economic paradigm is credible. Momani finds that there appears to be consensus on the utility of the IMF's prescribed economic policies. Indeed, these views are epitomized in the following statement from a speech by Anne O. Krueger (2004), who at the time was the IMF Acting Managing Director: "Economic policymaking is, by its nature, uncertain. There can be no absolute guarantees, in the sense that policy X will produce a growth rate of Y\%. But we do know what works, and what doesn't." (Emphasis added).

Reflecting on the IMF involvement in Sub-Saharan Africa, Woods (2006, p. 178) finds that "[t]oo often specific policy advice has been fashioned according to easy blueprints rather than hard research - ideological presumptions rather than tested theories." Woods also points to key reasons for such inflexibility embedded in part in staff incentives. She argues that originality in program design would increase the probability of a loan being rejected by the IMF board, and innovation would shift the burden of responsibility in the event of program failure towards individual staff members responsible for drafting the program. In contrast, building on a standard policy template reduces the responsibility of individuals and shifts the burden to the institution at large. It amounts to a rational risk-averse strategy, especially for junior staff. They are hard-pressed for time and their experience and expertise is typically more theoretical than practical. ${ }^{26}$ In sum, when providing policy advice, IMF staff face very powerful incentives not to deviate from the standard policy template, and perhaps the same holds for the organization at large (Woods, 2006). Thus, besides providing a "micro-foundation" explaining why structural conditionality is rigid, Woods' analysis suggests that the conditions for effective policy trialing do not exist within the current IMF structure. ${ }^{27}$

Woods' (2006) insights suggest that bringing organizational reform at the staff level into focus must be productive. Indeed, Evans and Finnemore (2001, p. 2) assert that: "acknowledging the lessons from organizational theory leads firmly to the conclusion that the way in which the Fund's staff is recruited, trained, organized and rewarded must be a central determinant of how the Fund defines and executes its mandate." A key question is then: What would an organizational reform aimed at encouraging risk taking look like?

\footnotetext{
25 See Rodrik (2006, p. 977) for a similar view.

${ }^{26}$ IMF staff in Africa are generally younger, staff turnover (including mission chiefs) is much higher in Africa, and fewer staff resources are invested in programs there (Woods, 2006).

27 Despite an adherence to orthodoxy, the details of implementation recognize the specifics of individual country contexts. This also explains Stone's (2007, p. 9) finding that: "there is no basis for the charge that the IMF imposes a one-size-fits-all template of conditions." While the IMF adheres to the principle of privatization in many of its conditions, application is to sectors that are relevant in each country: the IMF understands that cotton is the key sector to target in Mali and Burkina Faso, while cocoa may be key in Ghana and Cote d'Ivoire. Policy trialing by IMF staff, on the other hand, is something different. It would mean that conditionality would be allowed to deviate from the principles of the augmented Washington Consensus.
}

By way of an answer, we call attention to an important first order principle for any such reform, a principle that is highlighted by Heilmann (2008) in his studies of policy experimentation in China. Specifically, in China's hierarchical structure initiation of experimental policies normally comes from within the government. Yet experimental efforts are usually set off by local policymakers, who obtain informal backing for their pilot projects from a higher-level government patron. Indeed, encouragement and protection by patrons is an important "policy hedging mechanism" since unhedged policy initiatives are risky career-wise. In hierarchical systems, bottom-up experimentation is unthinkable without the backing of higher-level patrons. Initiation of experimentation must be built around local initiative and central sponsorship. The lesson from this discussion is that organizational IMF reform at the staff level will incite policy trialing only if there is a change in the mindset at the Board level. Put differently, if the Board remains entrenched in orthodoxy, status quo will persevere.

Beyond the issues discussed by Woods (2006) such as increasing incentives for risk taking, Evans and Finnemore (2001) and Momani (2007) propose a broadening of staff recruitment. ${ }^{28}$ Evans and Finnegan in particular propose increasing the voice of developing member countries through staff recruitment, which would serve to increase "local knowledge." Local knowledge is important at the IMF since economic reforming has a "craft" character. In craft work " $[. .$.$] procedures are non-routine, and the work depends to a$ considerable degree on experimentation and intuition." (Evans and Finnemore, 2001, p. 9). Each national economy is unique, which is why IMF programs must be tailored to the particular national context. This is perhaps most pertinent when the IMF ventures beyond macroeconomic stabilization and into the area of institutional reform.

\section{Concluding remarks}

Recent IMF rhetoric about the goals of the institution has put emphasis on economic growth. While econometric evidence is subject to considerable methodological criticism, and must be interpreted with caution, broad evidence suggests that the institution has failed to deliver on this objective, largely due to a rigid and orthodox approach to economic policymaking. The unimpressive track record has led to calls for a refocusing of the IMF.

The IEO (2004, p. 17) evaluation of the Poverty Reduction Strategy observes that a major external criticism of the IMF is that "[a]lternative policy options - especially ones that deviate from the so-called 'Washington Consensus' - are rarely explored." Moreover, the IEO (2004, p. 18) states that "to understand the linkages between policies $[. .$.$] and growth/poverty reduction requires a$ good understanding of the macro-micro linkages in a particular country context, including the nature of country-specific institutional characteristics [...]." This internal evaluation certainly suggests an admission of previous problems.

The Malan (2007) report advises that the IMF should withdraw from development finance altogether. In contrast, Lombardi (2007a, 2007b) argues there is an important role to play for the IMF in developing countries. The IMF supplies a bundled set of activities, including lending, policy advice, and information-gathering services, many of which entail an element of public good. In any case, an IMF that is entrenched in orthodoxy will not be able to play a useful role in policy reform and development efforts across the developing countries at large. What is needed is an open-minded

\footnotetext{
${ }^{28}$ Former Managing Director Horst Kohler wanted to hire fewer macroeconomists. He found this group unimaginative and unable to think out of the box; instead, he wanted to hire more MBAs and former policy practitioners (Momani, 2007).
} 
IMF that is willing to deviate from orthodoxy. Both identifying binding constraints to growth and trial and error in setting development policy require collaboration among national governments, the IMF, the World Bank and bilateral donors, and taking a broad view of development strategy. Moreover, policy trialing may be easier to implement for projects and programs than it will be for streamlined IMF conditionality that focuses on its core competencies.

In order to incite a change in the IMF approach to reform in lowincome countries, we advocate organizational reform at both Board and staff level. Reforms aimed at changing the governance structure of the IMF are critically important if the institution is to stay relevant and trusted (El-Erian, 2007; Evans and Finnemore, 2001; Momani, 2007). The real challenge in reforming the IMF, however, is for its leadership to acknowledge the significance of failures from implementing augmented Washington Consensus type policies. Much is at stake if the IMF remains unreformed, a conclusion which the evolving global credit crisis and experiences in the developing countries over the past 25 years so vividly illustrate.

\section{Acknowledgements}

We thank John Rand, seminar participants at the Danish Development Days (Copenhagen, 10 June 2008), and two anonymous referees for useful comments. The usual caveats apply.

\section{References}

Acemoglu, D., Johnson, S., \& Robinson, J. (2003). Institutional causes, macroeconomic symptoms: Volatility, crises and growth. Journal of Monetary Economics, $50,49-123$.

Albouy, D. (2008). The colonial origins of comparative development: An Investigating of the settler mortality data (NBER Working Paper 14130).

Barro, R., \& Lee, J. (2005). IMF programs: Who is chosen and what are the effects? Journal of Monetary Economics, 52, 1245-1269.

Bird, G. (2007). The IMF: A bird's eye view of its role and operations. Journal of Economic Surveys, 21, 683-745.

Bird, G., \& Willett, T. (2004). IMF conditionality, implementation and the new political economy of ownership. Comparative Economic Studies, 46, 423-450.

Blackorby, C., \& Schworm, W. (1988). The existence of input and output aggregates in aggregate production functions. Econometrica, 56, 613-643.

Boughton, J. (2003). Who's in charge? Ownership and conditionality in IMFsupported programs. Washington, International Monetary Fund (Working Paper, $\mathrm{WP} / 03 / 191)$.

Bromley, D., \& Yao, Y. (2006). Understanding China's economic transformation: Are there lessons for the developing world? World Economics, 7, 73-95.

Carlin, W., \& Seabright, P. (2007). Bring me sunshine: Which parts of the business climate should public policy try to fix? Paper presented at the Annual World Bank Conference on Development Economics, Bred Slovenia.

Collier, P. (2007). The bottom billion. Oxford: Oxford University Press.

Conway, P. (2006). The international monetary fund in a time of crisis: A review of Stanley Fischer's IMF essays from a time of crisis: The international financial system, stabilization, and development. Journal of Economic Literature, 44, 115-144.

Dicks-Mireaux, L, Mecagni, M., \& Schadler, S. (2000). Evaluating the effect of IMF lending to low-income countries. Journal of Development Economics, 61, 495-526.

Dixit, A. (2007). Evaluating recipes for development success. World Bank Research Observer, 22, 131-157.

Dreher, A. (2003). The influence of elections on IMF program interruptions. Journal of Development Studies, 39, 101-120.

Dreher, A. (2006). IMF and economic growth: The effects of programs, Loans, and Compliance with Conditionality. World Development, 34, 769-788.

Easterly, W. (2001). The lost decades: Developing countries' stagnation in spite of policy reform 1980-1998. Journal of Economic Growth, 6, 135-157.

Easterly, W. (2005a). National policies and economic growth: A reappraisal. In P. Aghion, \& S. Durlauf (Eds.), Handbook of economic growth (pp. 1015-1059). Elsevier Publishers. doi:10.1016/S1574-0684(05)01015-4

Easterly, W. (2005b). What did structural adjustment adjust?: The association of policies and growth with repeated IMF and world bank adjustment loans. Journal of Development Economics, 76, 1-22.

Easterly, W. (2008). Institutions: Top down or bottom up? Mimeo: New York University.

Edwards, S. (1989). On the sequencing of structural reforms (NBER Working Paper, No. 3138).

Edwards, S. (2001). Crime and punishment: Understanding IMF sanctioning practices. Mimeo, Rutgers University.
El-Erian, M. (2007). When markets collide: Investment strategies for the age of global economic change. New York: McGraw-Hill.

Evans, P. (2004). Development as institutional change: The pitfalls of monocropping and the potentials of deliberation. Studies in Comparative International Development, 38, 30-52.

Evans, P., \& Finnemore, M. (2001). Organizational reform and the expansion of the South's voice at the Fund. G-24 Discussion Paper Series, No. 15, December.

Felipe, J., \& Fisher, F. (2003). Aggregation in production functions: What applied economists should know. Metroeconomica, 54, 208-262.

Fisher, F. (1969). The existence of aggregate production functions. Econometrica, 37 , 553-577.

Glaeser, E., La Porta, R., Lopes-De-Silanes, F., \& Shleifer, A. (2004). Do institutions cause growth? Journal of Economic Growth, 9, 271-303.

Goldstein, M. (2001). IMF structural conditionality: How much is too much? (Working Paper 01-4), Peterson Institute for International Economics.

Hausmann, R., Pritchett, L., \& Rodrik, D. (2005a). Growth accelerations. Mimeo, Harvard University.

Hausmann, R., Rodrik, D., \& Velasco, A. (2005b). Growth diagnostics. Mimeo, Harvard University.

Heilmann, S. (2008). Policy experimentation in China's economic rise. Studies in Comparative International Development, 43, 1-26.

Independent Evaluation Office (2004). Evaluation of the IMF's role in Poverty Reduction Strategy Papers and the Poverty Reduction and Growth Facility. Washington, D.C.: International Monetary Fund.

Independent Evaluation Office. (2007). An IEO evaluation of structural conditionality in IMF-supported programs. Washington, D.C.: International Monetary Fund.

International Monetary Fund. (2005, September). IMF conditionality. Factsheet.

Jones, C. (2008). Intermediate goods, weak links, and superstars: A theory of economic development (NBER Working Paper 13834).

Killick, T. (1995). IMF programmes in developing countries: Design and impact. London: Routledge.

Krueger, A. (2004). Meant well, tried little, failed much: Policy reforms in emerging market economies. Roundtable Lecture Economic Honors Society, New York University.

Leipziger, D., \& Zagha, R. (2006). Getting out of the rut. Finance and Development, 43. Available online at: http://www.imf.org/external/pubs/ft/ fandd/2006/03/index.htm

Lipsey, R., \& Lancaster, K. (1956). The general theory of second best. Review of Economic Studies, 24, 11-32.

Lombardi, D. (2007). The development dimension of IMF lending policies. International Spectator, 42, 95-113.

Lombardi, D. (2007b). The role of the IMF in low-income countries. Available online at: http://www.brookings.edu/ /media/Files/rc/speeches/2007/ 0924imf/0924imf.pdf

Malan Report. (2007). Report on the External Review Committee on BankFund Collaboration. Available online at: http://www.imf.org/external/np/pp/ eng/2007/022307.pdf

Mankiw, N. (1995). The growth of nations. Brookings Papers on Economic Activity, 26, 275-326.

Momani, B. (2005). Recruiting and diversifying IMF technocrats. Global Society, 19, $167-187$.

Momani, B. (2007). IMF staff: Missing link in fund reform proposals. Review of International Organizations, 2, 39-57.

Montiel, P., \& Servén, L. (2006). Macroeconomic stability in developing countries: How much is enough? World Bank Research Observer, 21, 178-551.

Pritchett, L. (2000). The tyranny of concepts: CUDIE (cumulated, depreciated, investment effort) is not capital. Journal of Economic Growth, 5, 361-384.

Przeworski, A., \& Vreeland, J. (2000). The effect of IMF programs on economic growth. Journal of Development Economics, 62, 385-421.

Qian, Y. (2003). How reform worked in China. In D. Rodrik (Ed.), Search of prosperity: Analytic narratives on economic growth (pp. 297-333). Princeton University Press.

Raa, T. (2005). The economics of input-output analysis. Cambridge University Press.

Rodrik, D. (2005). Growth strategies. In P. Aghion, \& S. Durlauf (Eds.), Handbook of economic growth (pp. 967-1014). Elsevier Publishers. doi:10.1016/S15740684(05)01014-2

Rodrik, D (2006). Goodbye Washington consensus, hello Washington confusion? A review of the World Bank's economic growth in the 1990s: Learning from a decade of reform. Journal of Economic Literature, XLIV, 973-987.

Rodrik, D., 2008. Second-best institutions. Mimeo, Harvard University.

Rodrik, D., Subramanian, A., \& Trebbi, F. (2004). Institutions rule: The primacy of institutions over geography and integration in economic development. Journal of Economic Growth, 9, 131-165.

Rodrik, D. (2007). One Economics, Many Recipes: Globalization, Institutions, and Economic Growth. Princeton, New Jersey: Princeton University Press.

Rybczynski, T. (1991). The sequencing of reform. Oxford Review of Economic Policy, $7,26-34$

Solow, R. (2001). Applying growth theory across countries. World Bank Economic Review, 15, 283-288.

Stiglitz, J. (2000). Reflections on the theory and practice of reform. In A. O. Krueger (Ed.), Economic policy reform: The second stage (pp. 551-584). University of Chicago Press.

Stiglitz, J. (2001). Failure of the fund: Rethinking the IMF response. Harvard International Review, 23, 14-18. 
Stiglitz, J. (2004). Capital-market liberalization, globalization, and the IMF. Oxford Review of Economic policy, 20, 57-71.

Stone, R. (2007). The scope of IMF conditionality. Mimeo, University of Rochester. Taylor, L. (1997). Editorial: The revival of the liberal creed - The IMF and the world bank in a globalized economy. World Development, 25, $145-152$.

Temple, J. (2006). Aggregate production functions and growth economics. International Review of Applied Economics, 20, 301-317.

Vreeland, J. (2003). The IMF and economic development. Cambridge University Press. Vreeland, J. (2006). IMF program compliance: Aggregate index versus pol- icy specific research strategies. Review of International Organizations, 1 359-378.

Wade, R. (1990). Governing the market. Princeton, New Jersey: Princeton University Press.

Woods, N. (2006). The globalizers: The IMF, the world bank and their borrowers. Princeton, New Jersey: Princeton University Press.

World Bank. (1993). The East Asian miracle: Economic growth and public policy. Washington, D.C.: Oxford University Press.

World Bank. (2005). Economic growth in the 1990s: Learning from a decade of reform. Washington, D.C.: Oxford University Press. 